\title{
A narrative review of postoperative bleeding in patients with gastric cancer treated with endoscopic submucosal dissection
}

\author{
Li Liu ${ }^{1 \#}$, Hongqun Liu ${ }^{1,2 \# \wedge}$, Zhijie Feng ${ }^{1}$ \\ ${ }^{1}$ Department of Gastroenterology, The Second Hospital of Hebei Medical University, Shijiazhuang, China; ${ }^{2}$ G.I. research group, Cumming School \\ of Medicine, University of Calgary, Calgary, Alberta, Canada \\ Contributions: (I) Conception and design: Z Feng; (II) Administrative support: L Liu, H Liu; (III) Provision of study materials or patients: L Liu, H \\ Liu; (IV) Collection and assembly of data: L Liu, H Liu; (V) Data analysis and interpretation: L Liu, H Liu; (VI) Manuscript writing: All authors; (VII) \\ Final approval of manuscript: All authors. \\ \#These authors contributed equally to the work. \\ Correspondence to: Zhijie Feng. Department of Gastroenterology, The Second Hospital of Hebei Medical University, 215 Heping West Road, \\ Shijiazhuang 050000, China. Email: Zhijiefeng2005@163.com.
}

\begin{abstract}
Endoscopic submucosal dissection (ESD) is now considered a standard treatment for selected patients with early gastric cancer. Compared with endoscopic mucosal resection (EMR), ESD provides a higher complete resection rate (R0), and therefore, a lower local recurrence rate. However, ESD is a more time-consuming procedure, creating a wider and deeper ulcer floor which may cause complications. Post-ESD bleeding is one of them. Although most post-ESD bleedings can be controlled by endoscopic hemostasis at the time of operation, some bleeding after ESD may result in serious conditions such as hemorrhagic shock. Even with preventive methods such as ulcer closure, the application of fibrin glue and polyglycolic acid shielding, acid secretion inhibitors and hemostasis on second-look endoscopy, our experiences told us that post-ESD bleeding cannot be entirely avoidable, especially for patients with big size ulcer bed, anticoagulants/antithrombosis and chronic kidney diseases. The present review first defined post-ESD bleeding, then the incidence, the risk factors, such as the location of operative lesion, the size and depth, chronic kidney diseases, the impacts of anticoagulant and antithrombotic agents. We finally reviewed the managements of post-ESD bleeding, including approaches of coagulating potential bleeding spots during the procedure, lesion closure, lesion shielding and the application of gastric acid secretion inhibitors.
\end{abstract}

Keywords: Gastric cancer; post-ESD bleeding; risk factors; lesion closure; lesion shielding

Submitted Aug 03, 2021. Accepted for publication Dec 28, 2021.

doi: 10.21037/jgo-21-466

View this article at: https://dx.doi.org/10.21037/jgo-21-466

\section{Introduction}

Endoscopic submucosal dissection (ESD) was first reported by Hirao and colleagues in Japan in 1988 (1). ESD is widely used in the treatment of early gastric cancer (EGC) because it preserves the stomach and allows one-piece resection with tumor-free margins, even in cases with large and ulcerative lesions and therefore, reduces the risk of local recurrence (1). ESD also permits accurate histological assessments (2).
Compared with endoscopic mucosal resection (EMR), ESD offers a higher complete resection rate, higher en bloc resection rate, and a lower local recurrence rate (3).

Although the incidence of intraoperative bleeding is significantly higher with ESD than that with EMR because of longer operation and more invasive (4), the postoperative bleeding rate is comparable between the two techniques (3-5). ESD is therefore, considered a standard

^ ORCID: 0000-0002-6805-5177. 
treatment for EGCs (6). However, ESD causes relatively large lesions and lesion-related ulcers, ulcer scars. The long operation time also increases the risk of adverse events such as post-ESD bleeding. The ESD related bleeding includes intraoperative bleeding and post-ESD bleeding. Intraoperative bleeding is treated during the procedure.

The present review concentrated on post-ESD bleeding. We were to summarize the incidence, the risk factors of the delayed bleeding in patients with ESD and the preventive and therapeutic strategies. We present the following article in accordance with the Narrative Review reporting checklist (available at https://jgo.amegroups.com/article/ view/10.21037/jgo-21-466/rc).

\section{Methods}

The literature on post-ESD bleeding, including systematic reviews and meta-analyses, randomized controlled trials, retrospective study, cohort studies and case series were extensively reviewed.

\section{Discussion}

\section{Definition and incidence}

The definition of post-ESD bleeding is not unique. Ojima and coworkers (6) defined as clinical evidence of bleeding that required endoscopic treatment with metal clips and/ or electrocoagulation; Mochizuki et al. (7) defined as hemorrhage with clinical symptoms and confirmed by emergency endoscopy from the completion of ESD until postoperative day 28 . The clinical symptoms include hematemesis, melena, or a decrease in haemoglobin of $>2 \mathrm{~g} / \mathrm{dL}$ since the last laboratory test. Yano et al. (8) defined as one of the followings: hematemesis or melena after ESD and needs blood transfusion or emergency endoscopy; second-look endoscopy confirms the presence of bloody gastric juice; spurting bleeding from the ulcer floor is observed and needs hemostasis; sudden drop of the hemoglobin level by $2 \mathrm{~g} / \mathrm{dL}$ or more on blood testing. Although there is no universally recognized definition, it is clear that post-ESD bleeding is a serious complication and may be life-threatening.

Another definition is the time of bleeding. Okada et al. (9) categorized post-ESD bleedings into early delayed bleeding ( $\leq 4$ postoperative days) and late delayed bleeding ( $\geq 5$ postoperative days). Libanio et al. (10) suggested that bleeding happened within 24 hours after ESD is categorised early bleeding, $>24$ hours called delayed bleeding. Yano et al. (8) classified post-ESD bleeding as acute post-ESD bleeding (0-5 days after ESD) and delayed post-ESD bleeding (6 or more days after ESD). Shiroma et al. (11) analyzed 10,320 ESD cases, they also defined 0-5 days after ESD as early post-ESD bleeding and found that the median time to post-ESD bleeding was 4 days. We agree to define $0-5$ days after ESD as early post-ESD because this definition set an alert for the endoscopists to closely monitor the patients for 5 days after ESD.

The rate of post-ESD bleeding is also various (0-15.6\%) (12-15); this rate for patients with antithrombotic agents or anticoagulants is even higher. Takeuchi et al. (16) found that post-ESD bleeding in antithrombotic group was $23.3 \%$, significantly higher than $2.0 \%$ in the non-antithrombotic group. Toya and colleagues (17) reported that post-ESD bleeding was significantly more frequent for lesions in patients with anticoagulant therapy than in those without anticoagulant $(11.7 \%$ vs. $1.5 \%$, respectively; $\mathrm{P}<0.001)$. Recently, Shiroma and colleagues (11) analyzed 10,320 ESD cases and found that the post-ESD bleeding rates were 3.2\% in not taking any antithrombotic agents; antiplatelet agents increased this rate from $3.2 \%$ to $8.7 \%$; anticoagulants increased the bleeding rate to $15.5 \%$; and antiplatelet agents plus anticoagulants escalate the post-ESD bleeding rate to $29.9 \%$. Overall, the post-ESD bleeding rates are diverse because of the different medications. The experiences of the endoscopists also impact the procedure time and the rates of post-ESD bleeding.

\section{Risk factors}

\section{ESD location}

Lesions are at the lower-third of the stomach. Nam and colleagues (18) found that the lesions in the lower third of the stomach (OR, 2.845; 95\% CI: 1.381-5.860; P=0.005) are prone to post-ESD bleedings. Yano et al. (8) found that a lesion in the distal stomach is an independent risk factor (OR, 2.0) of post-ESD bleeding. About $82 \%$ of the postESD bleedings are in the lower-third of the stomach (18). However, Sato et al. (19) found that the incidence of postESD bleeding is the same among upper, middle and lower stomach $(4.1 \%, 5.4 \%, 5.3 \%)$. A systemic review performed by Libanio et al. (10) also found no differences based on location $(5.2 \%, 5.6 \%, 5.5 \%$ respectively). The high frequency of post-ESD bleeding in the lower stomach is because the majority of gastric cancers are located in the lower stomach (upper $17.3 \%$, middle $31.2 \%$ and lower $51.5 \%)(19)$. A lesion in the lesser curvature is also prone to 
Table 1 The impact of lesion location on post-ESD bleeding

\begin{tabular}{|c|c|c|c|c|}
\hline Author & Lower-third (\%) & Middle-third (\%) & Upper-third (\%) & $P$ value \\
\hline Tsuji et al. (22) & 9.6 & 3.2 & 4.6 & $<0.05$ \\
\hline Furuhata et al. (23) & 7.3 & 4.5 & 3.1 & $<0.01$ \\
\hline Sato et al. (19) & 5.3 & 5.4 & 4.1 & $>0.05$ \\
\hline Matsumura et al. (24) & 6.1 & 3.3 & 4.6 & $>0.05$ \\
\hline Toyokawa et al. (25) & 5.2 & 4.9 & 5.0 & $>0.05$ \\
\hline Mukai et al. (26) & 16.9 & 13.5 & 0 & $>0.05$ \\
\hline
\end{tabular}

ESD, endoscopic submucosal dissection.

post-ESD bleeding after ESD (OR, 1.74) (10,20). Because this area has more penetrating vessels and is surrounded with solid fibrotic tissue which makes the incisions and dissections more difficult (21). Univariate and multivariate analyses showed that the lesion in the upper third of the stomach and post-ESD coagulation are independent factors of lower delayed bleeding (2). The lesions in the middle and in the lower thirds of the stomach have similar post-ESD bleeding rates (upper third, $1.1 \% v s$. middle or lower, $7.4 \%$; $\mathrm{P}<0.005)$. Although the correlation between ESD location and post-ESD bleeding is inconsistent in the literature, the studies tend to support that ESD at the lower third of the stomach is prone to post-ESD bleeding (Table 1) and therefore, the endoscopists should monitor more closely and pay more attention to the patient whose lesion is at the lower third of the stomach.

\section{ESD size and depth}

Theoretically, the larger the lesion size, the risker the post-ESD bleeding. Lesion size is an independent risk factor after procedure (17). Using multivariate analysis, Yano et al. (8) found that specimen diameter $\geq 40 \mathrm{~mm}$ is an independent risk factor of post-ESD bleeding (OR, 2.48, $\mathrm{P}<0.001)$. Yamamoto et al. (27) also elucidated that tumor size $>40 \mathrm{~mm}$ is a risk factor of post-ESD bleeding (OR, 4.25, $\mathrm{P}<0.01)$. Multivariate analysis by Tomida et al. (28) showed that age $\geq 65$, receiving multiple antithrombotic agents, resection of multiple lesions and lesion size $\geq 30 \mathrm{~mm}$ were independent risk factors. Furthermore, patients taking antithrombotic agents and having a large resection $(\geq 40 \mathrm{~mm})$ have a high rate of post-ESD bleeding (21-38\%) (29). Another factor is that the larger tumor needs longer time for operation, which is also a significant risk factor for postoperative bleeding (16). Yano et al. (8) demonstrated that procedure time $\geq 90 \mathrm{~min}$ is a risk factor of post-ESD bleeding. Deeper tumor invasion was associated with a higher risk of post-ESD bleeding (5.3\% in mucosal/ submucosal layer 1 group vs. $12.5 \%$ in submucosal layer 2/ muscularis propria group, $\mathrm{P}<0.001)(30)$.

\section{Chronic kidney disease (CKD)}

CKD is one of the risk factors in post-ESD bleeding (24,31-33). Choi et al. (31) compared 102 CKD patients underwent ESD for gastric neoplasms to 102 non-CKD patients, the propensity score was matched in these two groups. Sixty-one patients were at stage 3,19 at stage 4 and 22 at stage 5 . They found that the post-ESD bleeding rates were $6.6 \%, 26.3 \%$ and $22.7 \%$, respectively, this rate in non-CKD patients was $4.9 \%$. The post-ESD bleeding rates in CKD patients with stage 4 and 5 were significantly higher compared with that in non-CKD patients. Their multivariate analysis showed that stage $4 / 5$ CKD was a significant risk predictor of post-ESD bleeding (HR 4.99; 95\% CI: $1.32-18.8 ; \mathrm{P}=0.018)$. The pathogenesis of bleeding in CKD may be due to the uremic toxins that cause the abnormalities in platelet-platelet and platelet-vessel wall interactions (31). Other factors, such as abnormalities in blood coagulation, medications, and hemodialysis may also play roles (32). Yoshioka and coworkers (32) found that estimated glomerular filtration rate (eGFR) is correlated with post-ESD bleeding. They demonstrated that if the cutoff value of eGFR is set to $27.3 \mathrm{~mL} / \mathrm{min}$, the sensitivity and specificity for the prediction of post-ESD bleeding were $87.5 \%$ and $70.6 \%$, respectively. Numata et al. (33) analyzed 63 consecutive CKD patients with EGCs and treated by $\mathrm{ESD}$, they found that the post-ESD bleeding rate was $33 \%$ 
in patients with hemodialysis and $9 \%$ in those without hemodialysis $(\mathrm{P}<0.05)$. They concluded that hemodialysis is a risk factor of post-ESD bleeding. Choi et al. (31) concluded that patients with stage $3 \mathrm{CKD}$ have similar risk for post-ESD bleeding compared with non-CKD patients. However, patients with stage 4 and 5 CKD need to be closely monitored for bleeding events after ESD.

\section{Anticoagulant and antithrombotic agents}

In the aging society, patients using antithrombotic agents are increasing to prevent the cardio- and cerebrovascular diseases, which expose the patients with ESD into a vulnerable position of bleeding. Delayed bleeding after gastric ESD in patients with anticoagulants remains unavoidable (28). Continuing using aspirin is a risk factor of delayed bleeding (34). There is a dilemma of whether the anticoagulant/antiplatelet agents should be used in EGC patients undergoing ESD. On one hand, these patients need antithrombotic agents to prevent/treat cardio- and cerebrovascular diseases. Antithrombotic interruption may cause thrombosis. Igarashi et al. (35) reported that only antithrombotic interruption (3-7 days) cause thrombosis (4/245, 1.6\%). Jaruvongvanich et al. (36) did a meta-analysis which included 5 studies (included Igarashi's study) and 700 patients (266 in the aspirin-continued group and 434 in the aspirin-interrupted group). The rate of thrombotic events is $2.1 \%(9 / 434)$ in the aspirin-interrupted group and non thrombotic events in the aspirin-continued group. On the other hand, these agents increase the risk of delayed bleeding after gastric ESD. Toya et al. (17) analyzed 2,553 ESDs for EGC. After propensity score matching, they found that post-ESD bleeding was significantly more frequent in lesions of patients with than without anticoagulant therapy $(11.7 \%$ vs. $1.5 \%, \mathrm{P}=0.001)$. A multivariate analysis demonstrated that anticoagulant therapy is an independent risk factor of post-ESD bleeding. Other studies also confirmed that anticoagulant therapies are risk factor for post-ESD bleeding $(37,38)$. Tomida et al. (28) analyzed 728 patients who received anticoagulants and needed to be treated with ESD for gastric neoplasms. Among them, 261 were treated with direct oral anticoagulants (DOACs), and 467 with warfarin. They found that delayed bleeding occurred in $14 \%$ of patients treated with DOACs, and $18 \%$ of those with warfarin $(\mathrm{P}>0.05)$. Some guidelines recommend replacing warfarin or DOACs with heparin (heparin bridge therapy, HBT) to prevent thrombotic events when warfarin is discontinued (39). However, HBT also causes delayed bleeding for gastric ESD (40).
DOACs include the direct thrombin inhibitor, dabigatran, and the direct factor $\mathrm{Xa}$ inhibitors, such as rivaroxaban, apixaban, and edoxaban. Yoshio et al. (41) compared these two types of DOACs and found that the delayed bleeding rate is significantly higher in rivaroxaban users compared with those on dabigatran $45 \%$ vs. $0 \%$, $\mathrm{P}<0.05$ ). One reason may be that rivaroxaban is a longacting agent. Another reason is that dabigatran is given as an inactive prodrug, which is converted to active dabigatran by esterase-catalyzed hydrolysis in the liver, digestive tract, and the plasma $(28,42)$. Dabigatran may not have an anticoagulant effect locally in the stomach. In comparison, rivaroxaban is given as an active drug which directly target coagulation proteins around the lesion in the stomach after ESD. This difference explains the different risk of delayed bleeding (41). Substituting dabigatran for oral anticoagulants in the perioperative period is a reasonable option to reduce the risk of post-ESD bleeding (28).

Whether the patients need to switch the anticoagulant from warfarin to HBT is inconclusive. Nakamura et al. (43) found that replacing antithrombotic agents or anticoagulants by heparin before ESD reduce the risk of cardiovascular events, they did not find the increased delayed bleeding after ESD. In our clinical practice, we treat the patients with anticoagulant/antithrombosis the similar way as Nakamura and colleagues: we replaced anticoagulant/antithrombosis for one week before ESD and one week after ESD, if the patients do not have a sign of post-ESD bleeding, we switch back the original anticoagulant/antithrombosis therapies. We deliver low-molecular heparin with subcutaneous injection, 5,000 IU/day combined with proton pump inhibitor (PPI). We have not found the increased delayed bleeding after ESD nor the thrombosis events. Harada et al. (44) compared the continuing low dose warfarin to HBT, they found that the post-ESD bleeding tends to be higher in HBT group (9.1\% vs. $21.7 \%$ ), although the difference did not reach significance. Kubo et al. (45) evaluated the risk factors for delayed bleeding after therapeutic gastrointestinal endoscopy (including ESD, EMR, polypectomy and cold polypectomy) in patients receiving oral anticoagulants and found that continued anticoagulant therapy (OR 2.29), anticoagulant withdrawal with HBT (OR 2.18), and the combination of anticoagulant with 1 antiplatelet drug (OR 1.72) are independent risk factors for delayed bleeding (45). Yoshio et al. (41) found that HBT significantly increased the post-ESD bleeding (OR, 10.7). Douketis and coworkers (46) did a randomized, double-blind, placebo-controlled trial for the patients with atrial fibrillation who need to interrupt 
Table 2 The impact of antithrombotic agent on post-ESD bleeding (\%)

\begin{tabular}{|c|c|c|c|c|c|}
\hline Authors & DOACs & Warfarin & Antiplatelet/anticoagulant agents & HBT & $P$ value \\
\hline Kubo et al. (45) & 9.5 & 13.8 & & & $>0.05$ \\
\hline Yoshio et al. (41) & 20.8 & 24.6 & & & $>0.05$ \\
\hline Saito et al. (42) & 19.5 & 22.7 & & & $>0.05$ \\
\hline Igarashi et al. (35) & & & 9.2 & 10.8 & $>0.05$ \\
\hline Nakamura et al. (43) & & & 10.4 & 21.1 & $>0.05$ \\
\hline Kono et al. (50) & & & 18 & 29 & $>0.05$ \\
\hline Harada et al. (44) & & 9.1 & & 21.7 & $>0.05$ \\
\hline
\end{tabular}

ESD, endoscopic submucosal dissection; DOACs, direct oral anticoagulants; HBT, heparin bridge therapy.

warfarin treatment due to elective invasive procedures, they compared the patients with HBT and those without and showed that HBT does not reduce perioperative arterial thromboembolism but significantly increased bleeding events. Birnie et al. (47) found that continuous warfarin use is better than HBT. More evidence supports that continuous use of warfarin throughout the perioperative period is a better choice for patients on warfarin than HBT. In summary, most studies demonstrated that HBT is an independent risk factor of post-ESD bleeding (19,48-50) (Table 2). We suggest performing ESD without stopping antithrombotic agents because thrombosis is more serious than bleeding (35). Gastric ESD without cessation of antithrombotic agents may be more feasible.

\section{Diagnostic models of post-ESD bleeding}

There is no formular to calculate the risk of post-ESD bleeding. Fujishiro group (13) tried to establish a model (called BEST-J score) to stratify the risks of bleeding after ESD. They retrospectively enrolled 8,291 patients who underwent ESD for EGC derivation cohort from 25 institutions. They enrolled 2029 patients from eight institutions in other areas to validate the model. Their prediction model is based on 9 variables. 4 points for the warfarin or direct oral anticoagulants; 3 points for chronic kidney disease with haemodialysis; 2 points each for P2Y12 receptor antagonist and aspirin; 1 point each for cilostazol, a tumour size $>30 \mathrm{~mm}$, lower third in tumour location and presence of multiple tumours, -1 point for interruption of each kind of antithrombotic agents. They demonstrated that the patients with 0 to 1 point have low-risk of bleeding after ESD (2.8\%), with 2 points have intermediate-risk of bleeding (6.1\%), with 3 to 4 points have high-risk (11.4\%) and $\geq 5$ points have very high-risk $(29.7 \%)$ of post-ESD bleeding. Choe et al. (51) analysed 5,080 patients with ESD procedures, multivariate logistic regression showed that ongoing antithrombotic use during the procedure, cancer pathology on biopsy before ESD, and piecemeal resection were independent risk factors of post-ESD bleeding. They created a classification and regression tree (CART) model. Ongoing antithrombotic use, specimen size, and age are the components in this model. The theory of CART model is similar to BEST-J score (13). The number of terminal nodes in the tree decides the risk score, 1-1 and 1-2 were classified as low risk of bleeding, 1-3 and 1-4 as high risk of bleeding. The predictive accuracy of this model is close to $95 \%$ (51).

\section{Managements}

The physicians need to know the vascular architecture of the stomach before performing ESD. Normally, the vessels vertically penetrate the muscle layer and then flow horizontally along the middle submucosal layer where they form the vascular network. In the high vessel density areas, the perivascular fibrotic tissue and the vascular network form a fasciae-like layer (21). The physicians need to distinguish the penetrating vessels from the vessels in the network. The most important step is to visually identify the vessels before making decisions. The visible vessels need to be coagulated during the ESD procedure to prevent delayed bleeding (2). 
Table 3 The effect of ESD ulcer closure on post ESD bleeding

\begin{tabular}{llccc}
\hline Author & Closure method & Closure bleeding (\%) & Non-closure bleeding (\%) & P value \\
\hline Ego et al. (48) & Endoloop and endoclips & 11.5 & 11.9 & $>0.05$ \\
Lee et al. (58) & Detachable snare and clips & 0 & 4 & $>0.05$ \\
Shiotsuki et al. (52) & Endoloop & & 23 & $>0.05$ \\
& General & 8 & 16 & $<0.05$ \\
& Lesion $<40$ mm & 0 & 70 & 13.3 \\
\hline
\end{tabular}

ESD, endoscopic submucosal dissection; EMR, endoscopic mucosal resection.

\section{Coagulating potential bleeding spots}

The common sense is to coagulate potential bleeding spots. Lin et al. (30) used norepinephrine to increase blood pressure to $150 \mathrm{mmHg}$ for $5 \mathrm{~min}$ after the specimen was extracted and thus the non-obvious potential hemorrhage spots were exposed and coagulated. Compared with controls, the incidence of post-ESD bleeding in norepinephrine group was lower $(1.3 \%, 2 / 151$ vs. $10.1 \%$, $16 / 158, \mathrm{P}=0.01$ ).

\section{ESD ulcer closure}

The lesions after ESD cause bleeding, especially for those with diameter $\geq 40 \mathrm{~mm}$. There are several methods of lesion closure: endoloop, endoclips, Metal hemoclips and suture. Closing the lesion theoretically prevents the post-ESD bleeding. However, studies on the effect of lesion closure on the post-ESD bleeding are inconsistent. Ego et al. (48) studied the effectiveness of endoscopic closure using an endoloop and endoclips in preventing post-ESD bleeding in EGC patients who were taking antithrombotic therapy. They compared 131 ESDs in 110 patients in the closure group and 269 ESDs in 217 patients in the non-closure group and found that ulcer base closure using endoloop and endoclips did not prevent post-ESD bleeding (11.5\% vs. $11.9 \%, \mathrm{P}=0.89)$. Shiotsuki and coworkers (52) used endoloop to close the lesion after ESD and found that in general, the rate of post-ESD bleeding was lower in closure group. This difference reached significance in those the lesion $<40 \mathrm{~mm}(\mathrm{P}=0.03)$ or with Multiple antithrombotic agents $(\mathrm{P}=0.02)$.

The majority of the lesion suture studies are single arm. Akimoto et al. (53) sutured 22 lesions in 20 patients, no post-
ESD event occurred. Han et al. (54) sutured 18 lesions in the stomach after ESD, there was no delayed bleeding. They concluded that endoscopic suturing of post-ESD defects in the stomach is feasible, safe, and effective on preventing post-ESD bleeding. Maekawa et al. (55) sutured 11 patients, Kantsevoy et al. (56) sutured 4 lesions in the stomach, there was no immediate or delayed bleedings. Goto et al. (20) concluded that endoscopic hand-suturing (EHS), when successfully completed and sustained, is feasible and safe with favorable outcomes. EHS decreases the post-ESD bleeding even in patients undergoing antithrombotic therapy. Akimoto et al. (57) created 12 mucosal defects in 2 pigs. they compared the open (control) lesions with those sutured with EHS. They found that at post operative day 14, the lesions in EHS group were covered with the epithelium without inversion of the mucosal edge, whereas the ulcer bed in the control group was still exposed. The degree of neovascularity and fibroblasts in the submucosa was smaller in the EHS group compared with those in controls. They concluded that EHS enhances lesion healing after ESD which might be applicable to prevent post-ESD bleeding in clinical practice. In summary, more studies support the application of lesion closure in stomach lesions after ESD (Table 3).

\section{ESD ulcer shielding}

Tan and colleagues (60) sprayed porcine fibrin glue (FG) to the ulcer surface after ESD, they assigned 301 patients to non-FG group and 96 to FG group. They revealed that 18/301 patients had delayed bleeding after ESD in non-FG group, no bleeding in all 96 patients in $\mathrm{FG}$ group $(\mathrm{P}<0.05)$. However, the majority of the ESD physicians combine FG with polyglycolic acid (PGA) sheet. 
Table 4 The effect of ESD ulcer shielding on post ESD bleeding

\begin{tabular}{lcccc}
\hline Author & Shielding method & Shielding bleeding (\%) & Non-shielding bleeding (\%) & P value \\
\hline Kataoka et al. (62) & PGA & 4.5 & 5.7 & 6.0 \\
Tan et al. (60) & PG & 0 & 20.8 & $<0.05$ \\
Kawata et al. (63) & PG + PGA & 5.8 & 21 & $<0.05$ \\
Mori et al. (64) & PGA & 0 & 22 & $<0.05$ \\
Tsuji et al. (65) & PG + PGA & 6.7 & 12.9 & $<0.05$ \\
Fukuda et al. (68) & PG + PGA & 3.8 & $<.05$ \\
\hline
\end{tabular}

ESD, endoscopic submucosal dissection; PG, fibrin glue; PGA, polyglycolic acid.

Takimoto et al. (61) first used the combination of PGA sheet and FG in 2014 after duodenal endoscopic submucosal dissection. Kataoka et al. (62) compared the effect of lesion shielding with those without and found that post-ESD bleeding occurred in $4.5 \%$ patients with PGA sheet and $5.7 \%$ in the control group. They concluded that the PGA shielding method did not have a significant effect on the prevention of post-ESD bleeding.

Using keywords "polyglycolic acid + post-ESD bleeding + gastric cancer", there are 4 original articles in PubMed. Only Kataoka group showed that PGA shielding had no significant effect on the prevention of post-ESD bleeding, the other 3 consistently favor the application of PGA (63-65).

Takimoto and coworkers (66) used PGA sheet and fixed in place with fibrin glue, they found that the PGA sheets were still attached to the ulcer at 3 weeks after treatment. Kikuchi et al. (67) combined the autologous FG and PGA sheet to prevent post-ESD bleeding in patients with antithrombotic therapy. They first immersed the lesion size-matched PGA sheet in the autologous fibrinogen, then attached it onto the lesion and fixed it with clip, they finally sprayed the autologous fibrinogen and thrombin to the PGA sheet. They compared the post-ESD bleeding rate between the PGA sheet users and no PGA sheet users and found that PGA sheet significantly decreased the delayed bleeding $(1 / 38$ vs. $12 / 85, \mathrm{P}<0.05)$, blood transfusion $(0 / 38$ vs. $8 / 85, \mathrm{P}<0.05)$ and endoscopic hemostasis $(6 / 38$ vs. $35 / 38, \mathrm{P}<0.05$ ). Kawata et al. (63) compared the post-ESD bleeding between the patients with PGA sheet shielding after ESD and those without and found that post-ESD bleeding occurred in $5.8 \%$ in covering group and $20.8 \%$ in control groups $(\mathrm{P}<0.05)$. They concluded that the covering technique using PGA sheets and FG has the potential to decrease post-ESD bleeding in patients with continuing antithrombotic agents. Similar data also demonstrated in
Fukuda (68) and Tsuji (65) groups who demonstrated that PGA sheets decreased the delayed bleeding from $22 \%$ to $6.7 \%$ in high-risk patients after ESD. In summary, majority of the pertinent studies support this notion that sealing the ulcer lesion with PGA sheet after ESD reduces post-ESD bleeding (Table 4).

Sakagushi and coworkers (69) used envelope to deliver PGA sheets which avoided becoming wet and fold in animal model. Because of the gravity, the median PGA sheet application time was $1.00(0.68-1.30) \mathrm{min} / \mathrm{cm}^{2}$ with conventional method and $0.32(0.18-0.52) \mathrm{min} / \mathrm{cm}^{2}$ with the envelope techniques $(\mathrm{P}=0.002)$. The time for conquering the gravity was $1.20(1.13-1.63) \mathrm{min} / \mathrm{cm}^{2}$ with conventional techniques and $0.50(0.39-0.58) \mathrm{min} / \mathrm{cm}^{2}(\mathrm{P}=0.002)$ for the envelope method. The endoscopy and histology found that the fixation of the PGA sheets was not sufficient on conventional group. However, the envelope group had sufficient fixation. They concluded that the envelope technique delivers the PGA sheets to the stomach quickly and cover ulcers appropriately in living pigs (69). Glubran 2, a new endoscopic synthetic sealant, may be another material applicable in clinical practice in the future (70).

\section{Acid secretion inbibitors}

As it is well known that the gastric bleeding is affected by $\mathrm{pH}$ levels. Platelet aggregation, coagulation, and fibrinolysis on gastric hemorrhagic ulcers all strongly depend on intragastric $\mathrm{pH}$ levels (71). When $\mathrm{pH}$ is below 6.8, platelet aggregation and blood coagulation is abnormal; when $\mathrm{pH}$ is $<5.4$, platelet aggregation and plasma coagulation are virtually obliterated, when $\mathrm{pH}$ is $<4.0$, fibrin clots are dissolved (72). Therefore, it is very important to inhibit acid secretion in and after the procedure. There are currently three type of acid inhibitors, histamine2-receptor 
antagonists $\left(\mathrm{H}_{2} \mathrm{RAs}\right), \mathrm{PPI}$ and potassium-competitive acid blocker (P-CAB). Tomita et al. (73) compared the effectiveness of famotidine, a $\mathrm{H}_{2} \mathrm{RA}$, and omeprazole, a PPI, on post-ESD bleedings. This prospective randomized controlled trial study found that the delayed bleeding after ESD occurred in $6.5 \%$ of subjects with PPI administration and $6.3 \%$ in H2RA group. They therefore concluded that PPI is similar to H2RA for the prevention of delayed bleeding after ESD. The advantage of H2RA is that it is faster, H2RAs exert their inhibitory effects within a couple of hours after administration. Abe et al. (74) compared famotidine and omeprazole in 10 healthy, Helicobacter pylori-negative male subjects. They found that in all ten subjects, an intravenous dose of $20 \mathrm{mg}$ famotidine increased intragastric $\mathrm{pH}$ more rapidly than intravenous omeprazole $20 \mathrm{mg}$. The disadvantage is that, compared with PPIs, H2RAs are less potent. Uedo et al. (75) demonstrated that PPI therapy is more effective on preventing delayed bleeding after ESD compared with H2RA treatment.

Jiang and coworkers (71) performed a meta-analysis to compare the effects of PPIs and H2RAs on post-ESD bleeding. They found that PPIs are significantly more efficacious in preventing post-ESD bleeding compared with H2RAs (OR: $1.83 ; 1.10$ to $3.05, \mathrm{P}<0.05$ ). PPIs need longer time to reach their full potency. Four weeks application shows similar efficacy between PPIs and $\mathrm{H}_{2} \mathrm{Ras}$. However, PPIs are better than H2RAs in 8 weeks' treatment (OR: $1.91 ; 1.08$ to $3.40, \mathrm{P}<0.05)$. In summary, PPIs are better than H2RAs if the application is long enough. The maximum acid inhibition was achieved at day 5 after PPI administration (72). The physicians should use PPIs early enough to get the full potency to prevent post-ESD bleeding (76).

Another type of acid inhibitor is potassium-competitive acid blocker. Vonoprazan, a first-in-class P-CAB, is approved for clinical application in 2015 (77). these drugs bind reversibly to potassium and block the $\mathrm{H}^{+}, \mathrm{K}^{+}$ATPase enzyme, thus block acid production. Kakushima et al. (78) compared the delayed bleeding rate in patients who were using antithrombotics. They divided these patients into two groups, one used PPIs (71 patients with 101 lesions) and another used vonoprazan (59 patients with 90 lesions). The delayed bleeding occurred in 18\% patients in the PPI group and $31 \%$ patients in the vonoprazan group. There was no significant difference in the two groups (78). Another retrospective analysis showed that overall incidence of post-ESD bleeding was not significantly different between patients treated with $\mathrm{PPI}$ and $\mathrm{P}-\mathrm{CAB}(3.0 \%$ vs. $2.6 \%$,
$\mathrm{P}=0.77)$. After propensity score matching $(\mathrm{n}=153$ in each group), the incidence was not significantly different between the two groups ( $2.6 \%$ vs. $2.6 \%$ ) (79).

Suto and coworkers (80) compared the post-ESD bleeding between patients with PPIs and those with vonoprazan, they found that $15 \%$ of the patients with PPIs had post-ESD bleeding, the percentage was $4 \%$ for those with $\mathrm{P}-\mathrm{CAB}$. They concluded that vonoprazan has better protective effect on post-ESD bleeding than PPIs $(\mathrm{P}<0.05)$. Furthermore, they also found that the ulcer healing is better in patients treated with vonoprazan than those with PPIs. The reason why vonoprazan is better than PPIs is that vonoprazan is faster, stronger, and long-lasting inhibition of gastric acid secretion after administration (76) compared with PPIs. Kagami et al. (81) found that in overall genotype group, $\mathrm{pH} \geq 5$ holding time ratios with vonoprazan twice a day, vonoprazan daily, esomeprazole twice a day and esomeprazole daily were $99 \%, 91 \%, 84 \%$ and $54 \%$ respectively. Furthermore, the gastric $\mathrm{pH}$ tends to be higher for patients with vonoprazan compared with those with PPI (76). If the patients are given vonoprazan the night before ESD, the $\mathrm{pH}$ will increase to 6.96 on the day of $\operatorname{ESD}(80)$. On the contrary, it takes several days for the gastric $\mathrm{pH}$ to reach a high level with conventional PPIs (80). As a new class of acid-suppressing agents, vonoprazan reduces the incidence of delayed bleeding after ESD better than conventional PPIs (71). Moreover, vonoprazan effect is not affected by CYP2C19 polymorphisms (81). In addition, vonoprazan has better effects on mucosal protection than PPIs (71). Upper gastrointestinal endoscopy about 8 weeks after ESD showed that only one vonoprazan user $(1 / 32,3 \%)$ had ulcer scarring. In comparison, 11 PPI users $(11 / 64,17 \%)$ had open ulcers.

Overall, a meta-analysis revealed that vonoprazan is currently the best acid secretion inhibitor, the better one is PPI and $\mathrm{H}_{2} \mathrm{RA}$ ranks the third in preventing bleeding after ESD. The effects of the combination of vonoprazan with mucosal protective antiulcer drug may have even better efficacy on the prevention of post-ESD bleeding. Jiang et al. recommended that the patients with a high risk of bleeding, such as long operation time, large resection ulcer, deeper tumor location, and anticoagulant or antithrombotic drugs, need vonoprazan-mucosal protective antiulcer drugs for 8 weeks (71). According to the literature, we suggest vonoprazan the first line agent in clinical practice.

Routine second-look endoscopy (SLE) after gastric ESD remains controversial. The potential advantage is that endoscopists can evaluate the status of post-ESD ulcers 


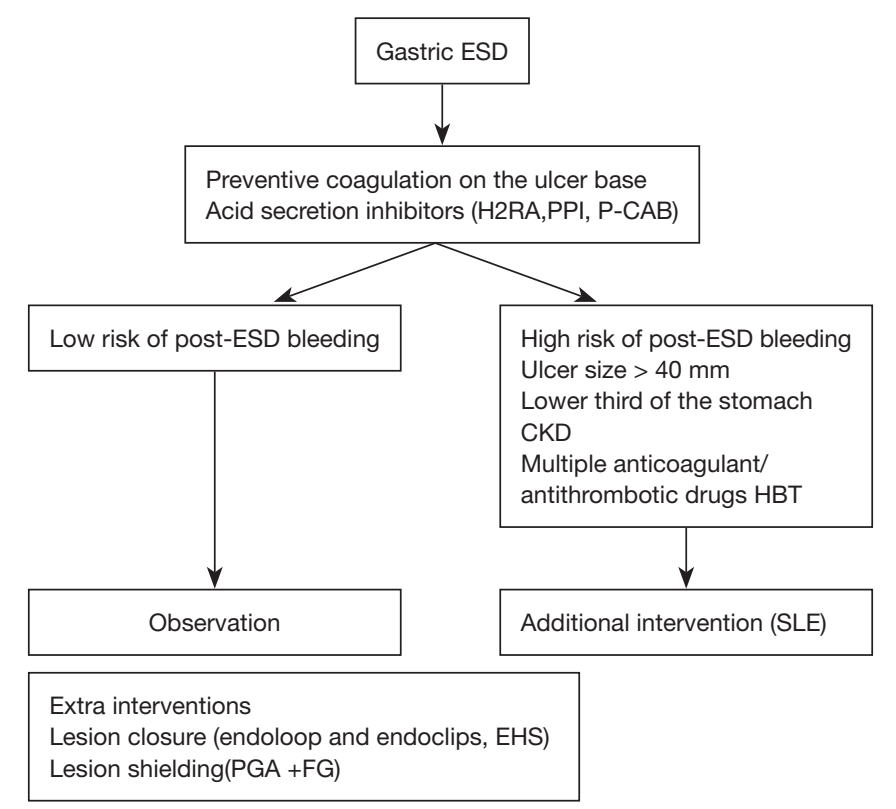

Figure 1 Managements of post- ESD bleeding. ESD, endoscopic submucosal dissection; H2RA, histamine-receptor antagonists; PPI, proton pump inhibitor; P-CAB, potassium-competitive acid blocker; CKD, chronic kidney disease; HBT, heparin bridge therapy; SLE, second-look endoscopy; EHS, endoscopic hand-suturing; PGA, polyglycolic acid; FG, fibrin glue.

and can take additional hemostatic measures if necessary. The study by Guo et al. (82) supports SLE. They reported that the incidence of late delayed bleeding was significantly decreased in the SLE group compared with that in the nonSLE group (4.5 vs. $12 \%, \mathrm{P}=0.028$ ). However, the majority of the pertinent studies denied the necessity of routine SLE. Mochizuki and coworkers (7) ran a multicentre prospective randomised controlled non-inferiority trial and revealed that the incidences of post-ESD bleeding were not significantly different between SLE and non-SLE groups (5.4\% vs. 3.8\%, P>0.05). Non-inferiority statistics showed that absolute risk difference between the non-SLE group and the SLE group was of $-1.6 \%\left(\mathrm{P}_{\text {non-inferiority }}<0.001\right)$. the

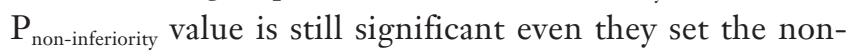
inferiority margin to $4 \%$. Kim et al. (83) did a meta-analysis on the role of SLE after ESD, they included 16 pertinent studies which included Mochizuki's study. This metaanalysis concluded that SLE has no role in reducing the risk of delayed post-ESD bleeding. On the contrary, delayed post-ESD bleeding is more common in patients who receive prophylactic hemostasis at SLE than in those who do not. Therefore, SLE is just for the patients with high risk of post-ESD bleeding (Figure 1), routine second-look endoscopy after gastric ESD may not be necessary.

\section{Summary}

ESD is the standard treatment for EGCs. However, this procedure is time consuming and may have some complications such as post-ESD bleeding. The risk factors include lesion location, ulcer size, CKD, and the usage of anticoagulant/antithrombotic agents. The managements including hemostasis during ESD, ulcer closure, ulcer shielding and antiacid drug administration.

\section{Acknowledgments}

Funding: This work was funded by the Beijing-TianjinHebei research cooperation project (No. H2018206450).

\section{Footnote}

Reporting Checklist: The authors have completed the Narrative Review reporting checklist. Available at https:// jgo.amegroups.com/article/view/10.21037/jgo-21-466/rc

Peer Review File: Available at https://jgo.amegroups.com/ article/view/10.21037/jgo-21-466/prf

Conflicts of Interest: All authors have completed the ICMJE 
uniform disclosure form (available at https://jgo.amegroups. com/article/view/10.21037/jgo-21-466/coif). All authors report that this paper was funded by Beijing-Tianjin-Hebei research cooperation project $\mathrm{H} 2018206450$. The authors have no other conflicts of interest to declare.

Ethical Statement: The authors are accountable for all aspects of the work in ensuring that questions related to the accuracy or integrity of any part of the work are appropriately investigated and resolved.

Open Access Statement: This is an Open Access article distributed in accordance with the Creative Commons Attribution-NonCommercial-NoDerivs 4.0 International License (CC BY-NC-ND 4.0), which permits the noncommercial replication and distribution of the article with the strict proviso that no changes or edits are made and the original work is properly cited (including links to both the formal publication through the relevant DOI and the license). See: https://creativecommons.org/licenses/by-nc-nd/4.0/.

\section{References}

1. Hirao M, Masuda K, Asanuma T, et al. Endoscopic resection of early gastric cancer and other tumors with local injection of hypertonic saline-epinephrine. Gastrointest Endosc 1988;34:264-9.

2. Takizawa K, Oda I, Gotoda T, et al. Routine coagulation of visible vessels may prevent delayed bleeding after endoscopic submucosal dissection--an analysis of risk factors. Endoscopy 2008;40:179-83.

3. Zhao Y, Wang C. Long-Term Clinical Efficacy and Perioperative Safety of Endoscopic Submucosal Dissection versus Endoscopic Mucosal Resection for Early Gastric Cancer: An Updated Meta-Analysis. Biomed Res Int 2018;2018:3152346.

4. Oka S, Tanaka S, Kaneko I, et al. Advantage of endoscopic submucosal dissection compared with EMR for early gastric cancer. Gastrointest Endosc 2006;64:877-83.

5. Nishizawa T, Yahagi N. Endoscopic mucosal resection and endoscopic submucosal dissection: technique and new directions. Curr Opin Gastroenterol 2017;33:315-9.

6. Ojima T, Takifuji K, Nakamura M, et al. Endoscopic submucosal tunnel dissection versus conventional endoscopic submucosal dissection for early gastric cancers: outcomes of 799 consecutive cases in a single institution. Surg Endosc 2020;34:5625-31.

7. Mochizuki S, Uedo N, Oda I, et al. Scheduled second- look endoscopy is not recommended after endoscopic submucosal dissection for gastric neoplasms (the SAFE trial): a multicentre prospective randomised controlled non-inferiority trial. Gut 2015;64:397-405.

8. Yano T, Tanabe S, Ishido K, et al. Different clinical characteristics associated with acute bleeding and delayed bleeding after endoscopic submucosal dissection in patients with early gastric cancer. Surg Endosc 2017;31:4542-50.

9. Okada K, Yamamoto Y, Kasuga A, et al. Risk factors for delayed bleeding after endoscopic submucosal dissection for gastric neoplasm. Surg Endosc 2011;25:98-107.

10. Libânio D, Costa MN, Pimentel-Nunes P, et al. Risk factors for bleeding after gastric endoscopic submucosal dissection: a systematic review and meta-analysis. Gastrointest Endosc 2016;84:572-86.

11. Shiroma S, Hatta W, Tsuji Y, et al. Timing of bleeding and thromboembolism associated with endoscopic submucosal dissection for gastric cancer in Japan. J Gastroenterol Hepatol 2021;36:2769-77.

12. Ono H, Yao K, Fujishiro M, et al. Guidelines for endoscopic submucosal dissection and endoscopic mucosal resection for early gastric cancer. Dig Endosc 2016;28:3-15.

13. Hatta W, Tsuji Y, Yoshio T, et al. Prediction model of bleeding after endoscopic submucosal dissection for early gastric cancer: BEST-J score. Gut 2021;70:476-84.

14. Shan J, Tang B, Liu L, et al. Development of chitosan/ glycerophosphate/collagen thermo-sensitive hydrogel for endoscopic treatment of mucosectomy-induced ulcer. Mater Sci Eng C Mater Biol Appl 2019;103:109870.

15. Zullo A, Manta R, De Francesco V, et al. Endoscopic submucosal dissection of gastric neoplastic lesions in Western countries: systematic review and meta-analysis. Eur J Gastroenterol Hepatol 2021;33:e1-6.

16. Takeuchi T, Ota K, Harada S, et al. The postoperative bleeding rate and its risk factors in patients on antithrombotic therapy who undergo gastric endoscopic submucosal dissection. BMC Gastroenterol 2013;13:136.

17. Toya Y, Endo M, Oizumi T, et al. Risk Factors for Postgastric Endoscopic Submucosal Dissection Bleeding with a Special Emphasis on Anticoagulant Therapy. Dig Dis Sci 2020;65:557-64.

18. Nam HS, Choi CW, Kim SJ, et al. Risk factors for delayed bleeding by onset time after endoscopic submucosal dissection for gastric neoplasm. Sci Rep 2019;9:2674.

19. Sato C, Hirasawa K, Koh R, et al. Postoperative bleeding in patients on antithrombotic therapy after gastric endoscopic submucosal dissection. World J Gastroenterol 2017;23:5557-66. 
20. Goto O, Oyama T, Ono H, et al. Endoscopic handsuturing is feasible, safe, and may reduce bleeding risk after gastric endoscopic submucosal dissection: a multicenter pilot study (with video). Gastrointest Endosc 2020;91:1195-202.

21. Horikawa Y, Fushimi S, Sato S. Hemorrhage control during gastric endoscopic submucosal dissection: Techniques using uncovered knives. JGH Open 2019;4:4-10.

22. Tsuji Y, Ohata K, Ito T, et al. Risk factors for bleeding after endoscopic submucosal dissection for gastric lesions. World J Gastroenterol 2010;16:2913-7.

23. Furuhata T, Kaise M, Hoteya S, et al. Postoperative bleeding after gastric endoscopic submucosal dissection in patients receiving antithrombotic therapy. Gastric Cancer 2017;20:207-14.

24. Matsumura T, Arai M, Maruoka D, et al. Risk factors for early and delayed post-operative bleeding after endoscopic submucosal dissection of gastric neoplasms, including patients with continued use of antithrombotic agents. BMC Gastroenterol 2014;14:172.

25. Toyokawa $T$, Inaba $T$, Omote $S$, et al. Risk factors for perforation and delayed bleeding associated with endoscopic submucosal dissection for early gastric neoplasms: analysis of 1123 lesions. J Gastroenterol Hepatol 2012;27:907-12.

26. Mukai S, Cho S, Kotachi T, et al. Analysis of delayed bleeding after endoscopic submucosal dissection for gastric epithelial neoplasms. Gastroenterol Res Pract 2012;2012:875323.

27. Yamamoto S, Takayama H, Shimodate Y, et al. Effect of Vonoprazan on Delayed Bleeding after Endoscopic Submucosal Dissection for Gastric Neoplasia among Antithrombotic Drug Users: A Single-Center, Single-Arm Prospective Observational Case Control Study. Acta Med Okayama 2020;74:245-50.

28. Tomida H, Yoshio T, Igarashi K, et al. Influence of anticoagulants on the risk of delayed bleeding after gastric endoscopic submucosal dissection: a multicenter retrospective study. Gastric Cancer 2021;24:179-89.

29. Li F, Xiong F, Xu ZL, et al. Polyglycolic acid sheets decrease post-endoscopic submucosal dissection bleeding in early gastric cancer: A systematic review and metaanalysis. J Dig Dis 2020;21:437-44.

30. Lin SL, Gao PT, Ni WK, et al. Controlled hypertension under hemostasis prevents post-gastric endoscopic submucosal dissection bleeding: a prospective randomized controlled trial. Surg Endosc 2021;35:5675-85.

31. Choi YK, Ahn JY, Na HK, et al. Outcomes of endoscopic submucosal dissection for gastric epithelial neoplasm in chronic kidney disease patients: propensity score-matched case-control analysis. Gastric Cancer 2019;22:164-71.

32. Yoshioka T, Nishida T, Tsujii M, et al. Renal dysfunction is an independent risk factor for bleeding after gastric ESD. Endosc Int Open 2015;3:E39-45.

33. Numata N, Oka S, Tanaka S, et al. Clinical outcomes of endoscopic submucosal dissection for early gastric cancer in patients with chronic kidney disease. J Gastroenterol Hepatol 2013;28:1632-7.

34. Hamada K, Kanzaki H, Inoue M, et al. Continued Aspirin Treatment May Be a Risk Factor of Delayed Bleeding after Gastric Endoscopic Submucosal Dissection under Heparin Replacement: A Retrospective Multicenter Study. Intern Med 2020;59:2643-51.

35. Igarashi K, Takizawa K, Kakushima N, et al. Should antithrombotic therapy be stopped in patients undergoing gastric endoscopic submucosal dissection? Surg Endosc 2017;31:1746-53.

36. Jaruvongvanich V, Sempokuya T, Wijarnpreecha K, et al. Continued versus interrupted aspirin use and bleeding risk after endoscopic submucosal dissection of gastric neoplasms: a meta-analysis. Ann Gastroenterol 2018;31:344-9.

37. Sanomura Y, Oka S, Tanaka S, et al. Taking Warfarin with Heparin Replacement and Direct Oral Anticoagulant Is a Risk Factor for Bleeding after Endoscopic Submucosal Dissection for Early Gastric Cancer. Digestion 2018;97:240-9.

38. Gotoda T, Hori K, Iwamuro M, et al. Evaluation of the bleeding risk with various antithrombotic therapies after gastric endoscopic submucosal dissection. Endosc Int Open 2017;5:E653-62.

39. Fujimoto K, Fujishiro M, Kato M, et al. Guidelines for gastroenterological endoscopy in patients undergoing antithrombotic treatment. Dig Endosc 2014;26:1-14.

40. Yoshio T, Nishida T, Kawai N, et al. Gastric ESD under Heparin Replacement at High-Risk Patients of Thromboembolism Is Technically Feasible but Has a High Risk of Delayed Bleeding: Osaka University ESD Study Group. Gastroenterol Res Pract 2013;2013:365830.

41. Yoshio T, Tomida H, Iwasaki R, et al. Effect of direct oral anticoagulants on the risk of delayed bleeding after gastric endoscopic submucosal dissection. Dig Endosc 2017;29:686-94.

42. Saito H, Igarashi K, Hirasawa D, et al. The risks and characteristics of the delayed bleeding after endoscopic submucosal dissection for early gastric carcinoma in cases 
with anticoagulants. Scand J Gastroenterol 2020;55:1253-60.

43. Nakamura M, Nishikawa J, Hamabe K, et al. Risk factors for delayed bleeding from endoscopic submucosal dissection of gastric neoplasms. Scand J Gastroenterol 2012;47:1108-14.

44. Harada H, Suehiro S, Murakami D, et al. Continuous use of low-dose warfarin for gastric endoscopic submucosal dissection: a prospective study. Endosc Int Open 2017;5:E348-53.

45. Kubo K, Kato M, Mabe K, et al. Risk Factors for Delayed Bleeding after Therapeutic Gastrointestinal Endoscopy in Patients Receiving Oral Anticoagulants: A Multicenter Retrospective Study. Digestion 2021;102:161-9.

46. Douketis JD, Spyropoulos AC, Kaatz S, et al. Perioperative Bridging Anticoagulation in Patients with Atrial Fibrillation. N Engl J Med 2015;373:823-33.

47. Birnie DH, Healey JS, Wells GA, et al. Pacemaker or defibrillator surgery without interruption of anticoagulation. N Engl J Med 2013;368:2084-93.

48. Ego M, Abe S, Nonaka S, et al. Endoscopic Closure Utilizing Endoloop and Endoclips After Gastric Endoscopic Submucosal Dissection for Patients on Antithrombotic Therapy. Dig Dis Sci 2021;66:2336-44.

49. Jaruvongvanich V, Sempokuya T, Wijarnpreecha K, et al. Heparin-Bridging Therapy and Risk of Bleeding After Endoscopic Submucosal Dissection for Gastric Neoplasms: a Meta-Analysis. J Gastrointest Cancer 2018;49:16-20.

50. Kono Y, Obayashi Y, Baba Y, et al. Postoperative bleeding risk after gastric endoscopic submucosal dissection during antithrombotic drug therapy. J Gastroenterol Hepatol 2018;33:453-60.

51. Choe YH, Jung DH, Park JC, et al. Prediction model for bleeding after endoscopic submucosal dissection of gastric neoplasms from a high-volume center. J Gastroenterol Hepatol 2021;36:2217-23.

52. Shiotsuki K, Takizawa K, Notsu A, et al. Endoloop closure following gastric endoscopic submucosal dissection to prevent delayed bleeding in patients receiving antithrombotic therapy. Scand J Gastroenterol 2021;56:1117-25.

53. Akimoto T, Goto O, Sasaki M, et al. Endoscopic hand suturing for mucosal defect closure after gastric endoscopic submucosal dissection may reduce the risk of postoperative bleeding in patients receiving antithrombotic therapy. Dig Endosc 2022;34:123-32.

54. Han S, Wani S, Edmundowicz SA, et al. Feasibility of endoscopic suturing to prevent adverse events and hospitalization after endoscopic submucosal dissection.
Endosc Int Open 2020;8:E1212-7.

55. Maekawa S, Nomura R, Murase T, et al. Complete closure of artificial gastric ulcer after endoscopic submucosal dissection by combined use of a single over-the-scope clip and through-the-scope clips (with videos). Surg Endosc 2015;29:500-4.

56. Kantsevoy SV, Bitner M, Mitrakov AA, et al. Endoscopic suturing closure of large mucosal defects after endoscopic submucosal dissection is technically feasible, fast, and eliminates the need for hospitalization (with videos). Gastrointest Endosc 2014;79:503-7.

57. Akimoto T, Goto O, Sasaki M, et al. Endoscopic suturing promotes healing of mucosal defects after gastric endoscopic submucosal dissection: endoscopic and histologic analyses in in vivo porcine models (with video). Gastrointest Endosc 2020;91:1172-82.

58. Lee BI, Kim BW, Kim HK, et al. Routine mucosal closure with a detachable snare and clips after endoscopic submucosal dissection for gastric epithelial neoplasms: a randomized controlled trial. Gut Liver 2011;5:454-9.

59. Choi KD, Jung HY, Lee GH, et al. Application of metal hemoclips for closure of endoscopic mucosal resectioninduced ulcers of the stomach to prevent delayed bleeding. Surg Endosc 2008;22:1882-6.

60. Tan ES, Wang H, Lua GW, et al. Fibrin Glue Spray as a Simple and Promising Method to Prevent Bleeding after Gastric Endoscopic Submucosal Dissection. Dig Surg 2016;33:455-61.

61. Takimoto K, Imai Y, Matsuyama K. Endoscopic tissue shielding method with polyglycolic acid sheets and fibrin glue to prevent delayed perforation after duodenal endoscopic submucosal dissection. Dig Endosc 2014;26 Suppl 2:46-9.

62. Kataoka Y, Tsuji Y, Hirasawa K, et al. Endoscopic tissue shielding to prevent bleeding after endoscopic submucosal dissection: a prospective multicenter randomized controlled trial. Endoscopy 2019;51:619-27.

63. Kawata N, Ono H, Takizawa K, et al. Efficacy of polyglycolic acid sheets and fibrin glue for prevention of bleeding after gastric endoscopic submucosal dissection in patients under continued antithrombotic agents. Gastric Cancer 2018;21:696-702.

64. Mori H, Guan Y, Kobara H, et al. Efficacy of innovative polyglycolic acid sheet device delivery station system: a randomized prospective study. Surg Endosc 2018;32:3076-86.

65. Tsuji Y, Fujishiro M, Kodashima S, et al. Polyglycolic acid sheets and fibrin glue decrease the risk of bleeding after 
endoscopic submucosal dissection of gastric neoplasms (with video). Gastrointest Endosc 2015;81:906-12.

66. Takimoto K, Toyonaga T, Matsuyama K. Endoscopic tissue shielding to prevent delayed perforation associated with endoscopic submucosal dissection for duodenal neoplasms. Endoscopy 2012;44 Suppl 2 UCTN:E414-5.

67. Kikuchi D, Iizuka T, Makino S, et al. Utility of autologous fibrin glue and polyglycolic acid sheet for preventing delayed bleeding associated with antithrombotic therapy after gastric ESD. Endosc Int Open 2019;7:E1542-8.

68. Fukuda H, Yamaguchi N, Isomoto H, et al. Polyglycolic Acid Felt Sealing Method for Prevention of Bleeding Related to Endoscopic Submucosal Dissection in Patients Taking Antithrombotic Agents. Gastroenterol Res Pract 2016;2016:1457357.

69. Sakaguchi H, Takao T, Takegawa Y, et al. Efficacy of the Envelope Method in Applying Polyglycolic Acid Sheets to Post-Endoscopic Submucosal Dissection Ulcers in Living Pigs. Clin Endosc 2021;54:64-72.

70. Boškoski I, Hamanaka J, Barbaro F, et al. Feasibility and safety of a new endoscopic synthetic sealant nebulizing device over gastric endoscopic submucosal dissections. Surg Endosc 2021;35:4048-54.

71. Jiang X, Li J, Xie J, et al. Histamine2-Receptor Antagonists, Proton Pump Inhibitors, or PotassiumCompetitive Acid Blockers Preventing Delayed Bleeding After Endoscopic Submucosal Dissection: A MetaAnalysis. Front Pharmacol 2019;10:1055.

72. Sugimoto M, Jang JS, Yoshizawa Y, et al. Proton Pump Inhibitor Therapy before and after Endoscopic Submucosal Dissection: A Review. Diagn Ther Endosc 2012;2012:791873.

73. Tomita T, Kim Y, Yamasaki T, et al. Prospective randomized controlled trial to compare the effects of omeprazole and famotidine in preventing delayed bleeding and promoting ulcer healing after endoscopic submucosal dissection. J Gastroenterol Hepatol 2012;27:1441-6.

74. Abe $Y$, Inamori M, Togawa J, et al. The comparative effects of single intravenous doses of omeprazole and famotidine on intragastric pH. J Gastroenterol 2004;39:21-5.

75. Uedo N, Takeuchi Y, Yamada T, et al. Effect of a proton pump inhibitor or an $\mathrm{H} 2$-receptor antagonist on prevention of bleeding from ulcer after endoscopic submucosal dissection of early gastric cancer: a prospective randomized controlled trial. Am J Gastroenterol 2007;102:1610-6.

76. Sakurai Y, Mori Y, Okamoto H, et al. Acid-inhibitory effects of vonoprazan $20 \mathrm{mg}$ compared with esomeprazole $20 \mathrm{mg}$ or rabeprazole $10 \mathrm{mg}$ in healthy adult male subjects-a randomised open-label cross-over study. Aliment Pharmacol Ther 2015;42:719-30.

77. Garnock-Jones KP. Vonoprazan: first global approval. Drugs 2015;75:439-43.

78. Kakushima N, Ono H, Takizawa K, et al. Incidence of Delayed Bleeding among Patients Continuing Antithrombotics during Gastric Endoscopic Submucosal Dissection. Intern Med 2019;58:2759-66.

79. Toya Y, Endo M, Sugai K, et al. Protective effect of proton pump inhibitors and potassium competitive acid blockers against post-gastric endoscopic submucosal dissection bleeding: a single-center, propensity score-matched analysis. Scand J Gastroenterol 2021;56:199-204.

80. Suto D, Yoshida M, Otake T, et al. Effects of vonoprazan on gastric $\mathrm{PH}$ and clinical course after gastric ESD: A retrospective and prospective study. Ann Med Surg (Lond) 2020;60:27-30.

81. Kagami T, Sahara S, Ichikawa H, et al. Potent acid inhibition by vonoprazan in comparison with esomeprazole, with reference to CYP2C19 genotype. Aliment Pharmacol Ther 2016;43:1048-59.

82. Guo Z, Miao L, Chen L, et al. Efficacy of second-look endoscopy in preventing delayed bleeding after endoscopic submucosal dissection of early gastric cancer. Exp Ther Med 2018;16:3855-62.

83. Kim EH, Park SW, Nam E, et al. Role of second-look endoscopy and prophylactic hemostasis after gastric endoscopic submucosal dissection: A systematic review and meta-analysis. J Gastroenterol Hepatol 2017;32:756-68.
Cite this article as: Liu L, Liu H, Feng Z. A narrative review of postoperative bleeding in patients with gastric cancer treated with endoscopic submucosal dissection. J Gastrointest Oncol 2022;13(1):413-425. doi: 10.21037/jgo-21-466 